\title{
Spatial mapping and prediction of Plasmodium falciparum infection risk among school-aged children in Côte d'Ivoire
}

\author{
Clarisse A. Houngbedji 1,2,3,4 Frédérique Chammartin 3,4, Richard B. Yapi ${ }^{2,3,4,5}$, Eveline Hürlimann 2,3,4, \\ Prisca B. N'Dri ${ }^{1,2,3,4}$, Kigbafori D. Silué2, ${ }^{2,}$, Gotianwa Soro ${ }^{6}$, Benjamin G. Koudou ${ }^{1,2,7}$, Serge-Brice Assi ${ }^{8,9}$, \\ Eliézer K. N'Goran ${ }^{2,5}$, Agathe Fantodji', Jürg Utzinger ${ }^{3,4}$, Penelope Vounatsou ${ }^{3,4}$ and Giovanna Raso ${ }^{3,4^{*}}$
}

\begin{abstract}
Background: In Côte d'Ivoire, malaria remains a major public health issue, and thus a priority to be tackled. The aim of this study was to identify spatially explicit indicators of Plasmodium falciparum infection among school-aged children and to undertake a model-based spatial prediction of $P$. falciparum infection risk using environmental predictors.

Methods: A cross-sectional survey was conducted, including parasitological examinations and interviews with more than 5,000 children from 93 schools across Côte d'Ivoire. A finger-prick blood sample was obtained from each child to determine Plasmodium species-specific infection and parasitaemia using Giemsa-stained thick and thin blood films. Household socioeconomic status was assessed through asset ownership and household characteristics. Children were interviewed for preventive measures against malaria. Environmental data were gathered from satellite images and digitized maps. A Bayesian geostatistical stochastic search variable selection procedure was employed to identify factors related to P. falciparum infection risk. Bayesian geostatistical logistic regression models were used to map the spatial distribution of $P$. falciparum infection and to predict the infection prevalence at non-sampled locations via Bayesian kriging.
\end{abstract}

Results: Complete data sets were available from 5,322 children aged 5-16 years across Côte d'lvoire. P. falciparum was the predominant species $(94.5 \%)$. The Bayesian geostatistical variable selection procedure identified land cover and socioeconomic status as important predictors for infection risk with P. falciparum. Model-based prediction identified high P. falciparum infection risk in the north, central-east, south-east, west and south-west of Côte d'lvoire. Low-risk areas were found in the south-eastern area close to Abidjan and the south-central and west-central part of the country.

Conclusions: The P. falciparum infection risk and related uncertainty estimates for school-aged children in Côte d'Ivoire represent the most up-to-date malaria risk maps. These tools can be used for spatial targeting of malaria control interventions.

Keywords: Bayesian modelling, Côte d'Ivoire, Malaria, Plasmodium falciparum, School-aged children

Abbreviations: ACT, Artemisinin-based combination therapy; BCI, Bayesian credible interval; GIS, Geographic information system; GPS, Global positioning system; IG, Inverse-gamma; IPT-SP, Intermittent preventive treatment with sulfadoxinepyrimethamine; LLIN, Long lasting insecticidal net; LST, Land surface temperature; MAE, Mean absolute error; MCMC, Markov chain Monte Carlo; NDVI, Normalized difference vegetation index; OR, Odds ratio; peNMIG, parameter expanded normal mixture of inverse gamma; PNSSU, "Programme National de Santé Scolaire et Universitaire"; SD, Standard deviation; SSVS, stochastic search variable selection; WHO, World Health Organization; YLDs, Years lived with disability

\footnotetext{
* Correspondence: giovanna.raso@unibas.ch

${ }^{3}$ Department of Epidemiology and Public Health, Swiss Tropical and Public

Health Institute, P.O. Box, CH-4002 Basel, Switzerland

${ }^{4}$ University of Basel, P.O. Box, CH-4003 Basel, Switzerland

Full list of author information is available at the end of the article
} 


\section{Background}

Malaria is a vector-borne disease that is widespread in sub-Saharan Africa. In 2015, an estimated 188 million malaria cases and 395,000 deaths occurred in Africa [1]. According to the Global Burden of Disease study, malaria is responsible for 31.7 million years lived with disability (YLDs) [2]. Malaria also drains the social and economic development of affected countries [3-5]. Over the past 15 years, malaria control interventions have averted 663 million clinical cases across Africa [6].

For the implementation of best-practice control strategies and intervention planning, in-depth knowledge of spatial characteristics and factors that influence malaria is needed. Predictive risk mapping has proven to be an important tool for malaria control $[7,8]$. In particular, the use of remote sensing technologies, coupled with geographic information system (GIS) allows to link high-resolution environmental data to the infection risk and produce model-based smooth predictive risk maps of the risk over a surface of interest [9-12]. Moreover, it allows a deeper understanding of the epidemiology and ecology of the disease [13-17]. Malaria prevalence data are likely to be spatially correlated and Bayesian geostatistical models can capture this correlation by accounting for an unobserved underlying spatial structure [18, 19]. These models are highly parameterized, and hence, model parameter estimations rely on complex algorithms such as Markov chain Monte Carlo (MCMC) sampling methods. Bayesian geostatistical methodology has been widely used for malaria risk mapping at local [20, 21], national [22], regional [23-26] and global scales [27, 28].

In Côte d'Ivoire, a country highly endemic for malaria, the national malaria prevention and control policy is based fundamentally on the use of long lasting insecticidal nets (LLINs), intermittent preventive treatment with sulfadoxine-pyrimethamine (IPT-SP) and environmental sanitation. The control strategy also includes prompt diagnosis and treatment with artemisinin-based combination therapy (ACT) [29]. No specific interventions targeting school-aged children are currently being promoted, but a recent national school-based survey in Côte d'Ivoire on parasitic diseases revealed an overall Plasmodium falciparum prevalence in excess of $60 \%$ [30, 31].

The purpose of this study was to spatially analyse $P$. falciparum prevalence data obtained from the first national school-based survey on parasitic infections in Côte d'Ivoire [30-32]. A Bayesian geostatistical approach was employed and environmental and sociodemographic factors, disease prevention indicators and distance from school to the nearest health facility were considered to assess their potential effects on $P$. falciparum infection risk. Environmental factors that govern the spatial distribution of $P$. falciparum were used to produce a modelbased high spatial resolution $P$. falciparum risk map for Côte d'Ivoire.

\section{Methods}

Study area

Côte d'Ivoire has a warm and humid climate. The average temperature ranges between $25^{\circ} \mathrm{C}$ and $32{ }^{\circ} \mathrm{C}$. There are three main seasons; warm and dry from November to March, hot and dry from March to May and hot and wet from June to October. A dense tropical moist forest covers the south-western part of the country; in the middle part of Côte d'Ivoire, a Guinean forest-savannah mosaic belt extends from east to west and a Sudanian savannah covers the northern part.

\section{Study design}

A country-wide cross-sectional survey using the lattice plus close pairs sampling approach was designed, as described elsewhere [30-33]. In short, a grid indicating latitude and longitude at a unit of $0.5^{\circ}$ was overlaid on a map of Côte d'Ivoire. A total of 94 schools were selected among all primary schools that comprised at least 60 children attending grades 3-5. Sixty children were sampled per school. This sample size exceeds the minimum sample size of 50 recommended by the World Health Organization (WHO) for collection of baseline information on helminth prevalence and intensity in schoolaged populations within large-scale surveys [34]. The survey was carried out during the dry season from November 2011 to February 2012. When visiting the schools, geographic coordinates were recorded, using a hand-held global positioning system (GPS) receiver (Garmin Sery GPS MAP 62; Olathe, USA).

\section{Parasitological, demographic, prevention, treatment and socioeconomic data}

To determine $P$. falciparum infection status, two drops of blood from finger prick samples were collected from enrolled children and thick and thin blood films were prepared on microscope slides. The slides were air-dried and transferred to nearby laboratories where they were stained with Giemsa and examined under a microscope by experienced laboratory technicians for Plasmodium species identification and parasitaemia. The number of parasitized blood cells were counted by assuming a standard white blood cell count of 8,000 per $1 \mu$ l of blood. Ten percent of the slides were randomly selected for quality control.

A pre-tested questionnaire was administered to all children participating in the survey. The questionnaire included information on household asset ownership 
(e.g. bicycle, fridge, radio, etc.), clinical symptoms (e.g. abdominal pain, headache, vomiting, etc.) and recent history of diseases (e.g. malaria, skin disease, schistosomiasis, etc.) [31]. Children were also asked whether they had a bed net at home, whether they slept under a bed net, whether they used other preventive measures against malaria, such as fumigating coils, insecticide spray and burning leaves and whether they took malaria treatment during the two weeks preceding the survey.

Data were double-entered and cross-checked in Epilnfo version 6 (Centers for Disease Control and Prevention; Atlanta, USA).

\section{Environmental data}

Environmental data were obtained from satellite imagery for the year 2011. The sources and the properties of these data are summarised in Table 1. Yearly average was used for night and day land surface temperature (LST), normalized difference vegetation index (NDVI) and rainfall. The rainfall coefficient of variation was calculated by dividing the standard deviation (SD) by the mean. Land cover was grouped into three categories: (i) urban; (ii) forest/savannah; and (iii) croplands. Altitude was obtained at $1 \mathrm{~km}$ spatial resolution and distance to freshwater bodies was extracted from digitized maps (Health Mapper database; Geneva, Switzerland).

\section{Statistical analysis}

Children were grouped into two age categories: (i) 5-10 years and (ii) 11-16 years. Distance from school to the nearest health facility was obtained from the "Programme National de Santé Scolaire et Universitaire" (PNSSU) and was summarised into three categories, i.e. (i) $<1 \mathrm{~km}$, (ii) $1-5 \mathrm{~km}$, and (iii) $>5 \mathrm{~km}$. The first category included schools located in villages or towns with a health facility. For assessment of socioeconomic status, an asset-based approach was used to stratify children into five socioeconomic groups [31].

Bayesian geostatistical stochastic search variable selection (SSVS) was performed to explore all possible models within a geostatistical framework and select the most important predictors for P. falciparum infection $[35,36]$. In addition, a parameter expanded normal mixture of inverse gamma (peNMIG) prior parameterization was used to address the oversampling of the categorical variables around zero that can arise with more traditional parameterizations [37]). Details related to the variable selection procedure are provided in Additional file 1.

A first variable selection that included demographic (age and sex) and environmental variables was performed to build a predictive model of the $P$. falciparum infection risk across Côte d'Ivoire (variable selection 1). In a second step, variables at individual level about prevention, treatment, distance from school to the nearest health facility and socioeconomic status, which were not available at $1 \times 1 \mathrm{~km}$ spatial resolution, were also explored for selection in order to assess their effect on $P$. falciparum infection risk (variable selection 2). The possible nonlinear relationships of variables were taken into account by considering the inclusion of categorical predictors in the model. We built both selection procedures to enable the model to choose the best functional form of each predictor, i.e. categorical or linear. With the exception of age, and distance from school to the health facilities that were categorised, predictors were introduced in both functional forms in the model for the variables, which could be expressed either as categorical or linear. The variables and their functional form included in the

Table 1 Data sources and properties of the environmental variables used to estimate Plasmodium falciparum risk among schoolaged children in Côte d'Ivoire

\begin{tabular}{|c|c|c|c|c|}
\hline Data type & Source & $\begin{array}{l}\text { Temporal } \\
\text { resolution }\end{array}$ & $\begin{array}{l}\text { Temporal } \\
\text { coverage }\end{array}$ & $\begin{array}{l}\text { Spatial } \\
\text { resolution }\end{array}$ \\
\hline Normalized difference vegetation index & MODIS/Terra ${ }^{a}$ & 16 days & 2011 & $1 \mathrm{~km}$ \\
\hline Day land surface temperature & MODIS/Terra ${ }^{a}$ & 8 days & 2011 & $1 \mathrm{~km}$ \\
\hline Night land surface temperature & MODIS/Terra ${ }^{a}$ & 8 days & 2011 & $1 \mathrm{~km}$ \\
\hline Land cover & MODIS/Terra ${ }^{a}$ & Year & 2011 & $1 \mathrm{~km}$ \\
\hline Rainfall & $\mathrm{ADDS}^{\mathrm{b}}$ & 10 days & 2011 & $8 \mathrm{~km}$ \\
\hline Rainfall coefficient of variation & Derived from rainfall & 10 days & 2011 & $1 \mathrm{~km}$ \\
\hline Altitude & DEM $^{c}$ & - & - & $1 \mathrm{~km}$ \\
\hline Freshwater bodies & HealthMapper $^{d}$ & - & - & - \\
\hline
\end{tabular}

${ }^{a}$ Moderate Resolution Imaging Spectroradiometer (MODIS). Available at: https://lpdaac.usgs.gov/ (accessed: 1 October 2012)

${ }^{b}$ Africa Data Dissemination Service (ADDS). Available at: http://earlywarning.usgs.gov/fews/datadownloads/Continental\%20Africa/Dekadal\%20RFE (accessed: 1 October 2012)

'Digital elevation model (DEM). Available at: http://eros.usgs.gov/ (accessed: 1 October 2012)

${ }^{\mathrm{d}}$ HealthMapper database. Available at: http://health-mapper-release-5.software.informer.com/ (accessed: 1 October 2012) 
final models were the ones with posterior probability of inclusion over $50 \%$ (median probability model).

Geostatistical logistic regression models within a Bayesian framework of inference were performed to analyse the risk of infection with $P$. falciparum via MCMC simulation algorithms for estimation of model parameters. Let $Y_{i j}$ be the $P$. falciparum infection status for child $j(j=1, \ldots, J)$ in school $i(i=1, \ldots, I)$. We assumed that $Y_{i j}$ arises from a Bernoulli distribution with probability $p_{i j}$ such as, $Y_{i j} \sim \mathrm{Be}\left(p_{i j}\right)$. We modelled covariates $X_{i j}$ and school-specific spatial random effects $\phi_{i}$ on the logit scale, i.e. $\log i t\left(p_{i j}\right)=X_{i j} \beta+\phi_{i}$, where $\beta$ represents the vector of regression coefficients, including a constant. Spatial random effects were assumed to follow a multivariate normal prior distribution, $\phi \sim \operatorname{MVN}(0, \Sigma)$. The variance-covariance matrix $\Sigma$ introduced spatial dependency through an isotropic exponential correlation function of distance between locations as follows: $\Sigma_{\mathrm{kl}}$ $=\sigma^{2} \exp \left(-\rho d_{k l}\right)$, where $d_{k l}$ is the Euclidian distance between a pair of schools $k$ and $l$, the variance $\sigma^{2}$ measures the spatial geographic variability and $\rho$ is a parameter that controls the rate of correlation decay. The range, defined as the minimum distance at which spatial correlation between locations is below $5 \%$, is calculated as $3 / p$. To complete model specification, prior distributions were assigned to model parameters. For the regression coefficients, non-informative normal prior distributions were chosen such as $\beta \sim \mathrm{N}(0,0.01)$ where $\beta=\left(\beta_{1}, \ldots \beta_{K}\right)^{\mathrm{T}}$. For the variance and the correlation decay, inverse gamma and gamma distributions were respectively assumed, i.e. $\sigma^{2} \sim \operatorname{IG}(2.01,1.01)$ and $\rho \sim \mathrm{G}(0.01,0.01)$. Model prediction was done using Bayesian kriging [38]. We assessed model convergence by visual examination of history and density plots. A sample of the last 500 iterations were stored for prediction on a grid of 352,911 pixels with a spatial resolution of $1 \mathrm{~km}$.

To validate our model, a geostatistical logistic regression model was fitted on a sub-dataset of 73 randomly selected schools (around $80 \%$ of the number of schools in the original dataset). We then predicted the risk at the remaining schools and compared our predictions with the observed prevalence data. Model predictive ability was assessed by calculating the mean absolute error (MAE), which is the mean of the absolute differences between the median of the predicted $P$. falciparum infection risk and the observed prevalence. Model uncertainty was assessed by the sum of the standard deviations (SDs) of the predictive distributions.

\section{Implementation details}

Geostatistical variable selection and model fit were implemented in OpenBUGS v.3.2.2 (University of Helsinki; Helsinki, Finland). Fortran 95 (Compaq Visual Fortran
Professional version 6.6.0, Compaq Computer Corporation; Houston, USA) was used for prediction. STATA version 10 (Stata Corporation; College Station, USA) was used for data management and preliminary analysis. ArcGIS version 10.0 (Environmental Systems Research Institute Inc; Redlands, USA) was used to display study results on maps.

\section{Results}

Complete data records were available from 5,322 children aged 5-16 years in 93 schools. Of note, one of the sampled schools refused to participate. The prevalences of $P$. malariae and $P$. ovale were very low; $3.7 \%$ and $0.3 \%$, respectively. $P$. falciparum was the predominant species with an overall observed prevalence of $69.2 \%$. All subsequent analyses focussed on P. falciparum only. The spatial distribution of the observed $P$. falciparum infection prevalence is shown on map A in Fig. 1.

We assessed potential correlation between predictors in a preliminary analysis, but none were considered as highly correlated, since the absolute value of the Pearson's correlation coefficient never exceeded $0.9(r<0.9)$. Hence, all of them were considered for selection as potential predictors of malaria risk. Median probability models with their posterior probability, as well as posterior inclusion probability of each predictor for both variable selection procedures are shown in Table 2. For variable selection 1, where only demographic and environmental predictors were explored, a posterior inclusion probability superior to $50 \%$ was obtained for land cover. However, when we additionally included prevention, treatment and socioeconomic data and distance from school to the nearest health facility in the variable selection procedure (variable selection 2), only socioeconomic status was retained as an important predictor.

Estimates of model parameters and model validation results for the Bayesian geostatistical logistic regression model with land cover as predictor are summarised in Table 3. Croplands and forest/savannah were positively associated to $P$. falciparum infection compared to urban setting (croplands odds ratio (OR): 1.95, 95 \% Bayesian credible interval (BCI): 1.23-3.03); forest/savannah OR: 2.30, $95 \%$ BCI: 1.43-3.81). The spatial range was $285 \mathrm{~km}$ (95 \% BCI: 139-477 km), indicating important residual spatial correlation. Model validation showed that the model predicts a random sample of $20 \%$ of the data with a MAE of 0.11 and a sum of SD of the posterior predictive distribution of 1.81 .

Estimates of model parameters for the Bayesian geostatistical logistic regression with socioeconomic status are also presented in Table 3. Socioeconomic status showed a significant association with the risk of $P$. falciparum infection; the wealthier the 


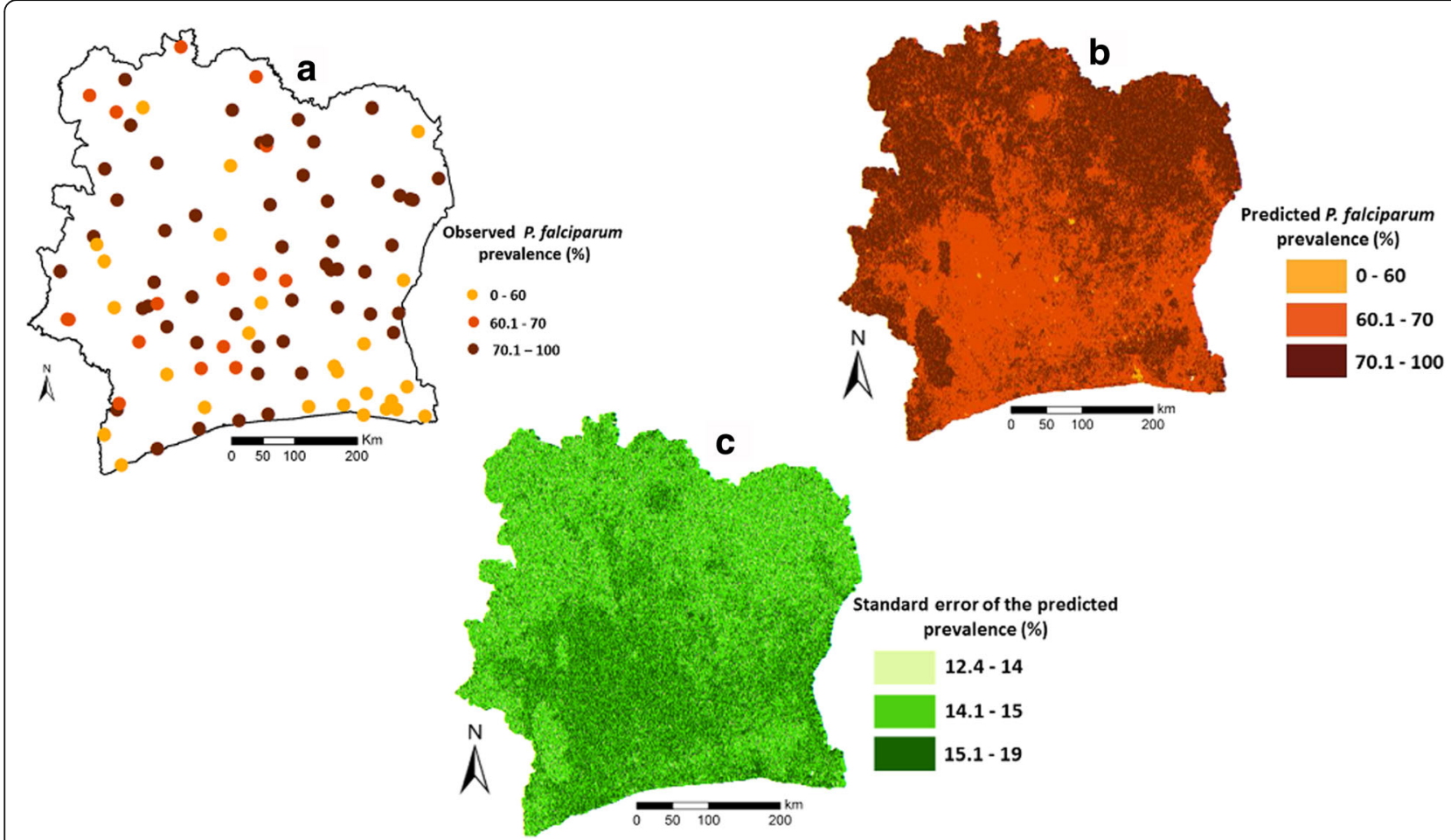

Fig. 1 Observed (a), predicted (b) and standard error of the predicted (c) Plasmodium falciparum infection prevalence among school-aged children in Côte d'Ivoire. Data used for prediction were obtained from a national cross-sectional survey carried out in 93 schools in the dry season between November 2011 and February 2012. Model-based predictions, including standard errors of predictions, were done within a Bayesian geostatistical framework

household, the lower the risk for P. falciparum infection. A substantial residual spatial correlation of $259 \mathrm{~km}$ (95 \% BCI: 123-457 km) was estimated.

Map B in Fig. 1 illustrates the smooth map of the estimated $P$. falciparum infection prevalence among school-aged children in Côte d'Ivoire. Lowest prevalences (around $45 \%$ ) were estimated for small urban aggregated areas in the south-east of the country, close to Abidjan, central-southern and centralwestern parts. Prevalences above $70 \%$ were found in the north, central-east, south-east, west and southwest of Côte d'Ivoire. Map C in Fig. 1 shows the standard error of the predicted P. falciparum infection prevalence. High prediction errors were mostly found from central-west to central-east of the country.

\section{Discussion}

The purpose of this study was to (i) identify sociodemographic, environmental and disease prevention indicators associated with $P$. falciparum infection prevalence and (ii) produce a smooth risk map of $P$. falciparum infection among school-aged children for Côte d'Ivoire. To our knowledge, this spatial analysis is the first at the national level based on $P$. falciparum data collected within a few weeks during the dry season in late 2011/early 2012. The results obtained from this spatially explicit analysis are useful for current and future malaria control efforts in Côte d'Ivoire.

Among the environmental covariates, only land cover was selected by the geostatistical variable selection procedure. Precipitation, temperature and distance to freshwater bodies - factors that have previously been associated to malaria risk in Côte d'Ivoire [21, 22] - were not identified as important predictors in the current investigation. Possible explanations arise from the use of different data sources; while the national survey reported here was conducted in the dry season, the aforementioned study pursued at country level [22] used historical data obtained over a period of 20 years and during different periods of the year. In addition, particular geographic patterns such as for the mountainous area in western Côte d'Ivoire [21], where particular climatic and environmental conditions prevail and scale differences across studies may further explain contrasting results. Regarding the distance to water body, this variable had not been selected by our modelling framework as a potential risk factor for malaria. This observation might be explained by the fact that the distance from school to water body is not precise enough to 
Table 2 Geostatistical variables selection results

\begin{tabular}{|c|c|c|c|c|}
\hline \multirow[b]{2}{*}{ Predictors } & \multicolumn{2}{|l|}{ Variable selection 1} & \multicolumn{2}{|l|}{ Variable selection 2} \\
\hline & $\begin{array}{l}\text { Median probability } \\
\text { model }\end{array}$ & $\begin{array}{l}\text { Predictor posterior inclusion } \\
\text { probability }\end{array}$ & $\begin{array}{l}\text { Median probability } \\
\text { model }\end{array}$ & $\begin{array}{l}\text { Predictor posterior inclusion } \\
\text { probability }\end{array}$ \\
\hline Age & 0 & $2.4 \%$ & 0 & $1.6 \%$ \\
\hline Gender & 0 & $27.6 \%$ & 0 & $24 \%$ \\
\hline \multicolumn{5}{|l|}{ Altitude } \\
\hline Linear & 0 & $1.6 \%$ & 0 & $1.5 \%$ \\
\hline Categorical & 0 & $4.2 \%$ & 0 & $2.4 \%$ \\
\hline \multicolumn{5}{|l|}{ Distance to freshwater bodies } \\
\hline Linear & 0 & $0.9 \%$ & 0 & $0.6 \%$ \\
\hline Categorical & 0 & $5.9 \%$ & 0 & $2.4 \%$ \\
\hline \multicolumn{5}{|l|}{ Rainfall } \\
\hline Linear & 0 & $2.2 \%$ & 0 & $2.3 \%$ \\
\hline Categorical & 0 & $25.0 \%$ & 0 & $14.8 \%$ \\
\hline \multicolumn{5}{|l|}{ Rainfall coefficient of variation } \\
\hline Linear & 0 & $1.9 \%$ & 0 & $2.1 \%$ \\
\hline Categorical & 0 & $9.8 \%$ & 0 & $20.6 \%$ \\
\hline \multicolumn{5}{|c|}{ Normalized difference vegetation index } \\
\hline Linear & 0 & $1.2 \%$ & 0 & $0.5 \%$ \\
\hline Categorical & 0 & $4.1 \%$ & 0 & $4.0 \%$ \\
\hline \multicolumn{5}{|l|}{$\begin{array}{l}\text { Night land surface } \\
\text { temperature }\end{array}$} \\
\hline Linear & 0 & $2.8 \%$ & 0 & $1.0 \%$ \\
\hline Categorical & 0 & $9.0 \%$ & 0 & $1.5 \%$ \\
\hline \multicolumn{5}{|l|}{ Day land surface temperature } \\
\hline Linear & 0 & $1.3 \%$ & 0 & $0.9 \%$ \\
\hline Categorical & 0 & $1.7 \%$ & 0 & $3.0 \%$ \\
\hline Land cover & $\times$ & $51.1 \%$ & 0 & $19.1 \%$ \\
\hline Bed net ownership & & & 0 & $2.1 \%$ \\
\hline Fumigating coil & & & 0 & $13.4 \%$ \\
\hline Insecticide spray & & & 0 & $15.5 \%$ \\
\hline Smoke by burning leaves & & & 0 & $3.3 \%$ \\
\hline Children sleeping under a net & & & 0 & $1.1 \%$ \\
\hline $\begin{array}{l}\text { Children slept under a net last } \\
\text { night }\end{array}$ & & & 0 & $1.8 \%$ \\
\hline Malaria treatment & & & 0 & $3.5 \%$ \\
\hline $\begin{array}{l}\text { Distance to nearest health } \\
\text { facility }\end{array}$ & & & 0 & $3.3 \%$ \\
\hline Socioeconomic status & & & $\times$ & $100 \%$ \\
\hline
\end{tabular}

Variable selection 1 included only demographic and environmental variables. Variable selection 2 additionally included prevention and socioeconomic variables. $\times$ (selected), 0 (not selected); Median probability model is presented together with posterior inclusions probability of the predictors

capture this effect or that the source of water body is not sufficiently detailed. Unfortunately, we could not afford to collect information on the distance from each participant's home to the nearest water body. Further effort is needed to identify additional water body information in Africa.
The spatial model with land cover as covariate indicated that school-aged children living in areas with forest/savannah and croplands are at higher risk of $P$. falciparum compared to those from urban areas. On one hand, this result suggests that the endemicity of malaria in Côte d'Ivoire is linked to two 
Table 3 Parameter estimates of two Bayesian geostatistical models with environmental and socioeconomic predictors

\begin{tabular}{lllll}
\hline Parameter & Model 1 & \multicolumn{3}{l}{ Model 2} \\
\hline & OR & $95 \% \mathrm{BCl}$ & OR & $95 \% \mathrm{BCl}$ \\
Land cover & & & \\
Urban & 1.00 & & \\
Croplands & 1.95 & $(1.23 ; 3.03)^{\mathrm{a}}$ & \\
Forest/savannah & 2.30 & $(1.43 ; 3.81)^{\mathrm{a}}$ & & \\
Socioeconomic status & & & \\
Poorest & & & 0.77 & $(0.61 ; 0.96)^{\mathrm{a}}$ \\
Poor & & & 0.66 & $(0.53 ; 0.84)^{\mathrm{a}}$ \\
Middle & & & 0.48 & $(0.39 ; 0.59)^{\mathrm{a}}$ \\
Wealthier & & & 0.44 & $(0.35 ; 0.56)^{\mathrm{a}}$ \\
Wealthiest & & & Median & $95 \% \mathrm{BCl}$ \\
& Median & $95 \% \mathrm{BCl}$ & $(0.24 ; 0,75)^{\mathrm{a}}$ \\
Spatial variance $\sigma^{2}$ & 0.46 & $(0.29 ; 0,80)^{\mathrm{a}}$ & 0.41 & $(123 ; 457)$ \\
Range (km) & 285 & $(139 ; 471)$ & 259 & \\
& Predictive & & & \\
& ability & & & \\
MAE & 0.11 & & & \\
Sum of SD & 1.81 & & &
\end{tabular}

Important covariate based on $95 \% \mathrm{BCl}$

Model 1: Bayesian geostatistical model with environmental predictor Model 2: Bayesian geostatistical model with socioeconomic predictor Abbreviations: OR odds ratio, $95 \% \mathrm{BCl}$ lower and upper bound of a $95 \%$ Bayesian credible interval, MAE mean absolute error, Sum of SD sum of standard deviation

main vegetation types, namely the forest in the south and the savannah in the north, which basically do characterise the two main ecozones of the country. In contrast, other studies using land cover showed that the forest area was associated with a decrease of malaria incidence [39] or risk [40]. It is important to underline that the south of Cote d'Ivoire is mainly characterised by tropical rainforest in which people are living and this pattern might differ in other studies. On the other hand, people living in urban areas generally have better access to treatment and prevention measures, compared to rural areas, which is reflected by our results.

Interestingly, the second geostatistical variable selection that included environmental variables, prevention and distance from school to the nearest health facility suggested that only socioeconomic status, as assessed by the wealth index, explained $P$. falciparum infection risk. Wealthier households were associated with a low risk of $P$. falciparum infection and is line with results from other studies [3, 41, 42]. Basically, this result is consistent with the first variable selection procedure, where only environmental factors were considered. Indeed, the urban area is characterised by overall higher socioeconomic status compared to the forest/savannah and cropland areas. Of note, Côte d'Ivoire is still mainly rural, although urbanisation progresses rapidly [20, 21, 31, 43]. As shown elsewhere, $P$. falciparum infection and parasitaemia are positively associated with low socioeconomic status.

In the present study employing recent epidemiological data, very high prevalences of $P$. falciparum (> $70 \%$ ) were found in the entire north and the south-west (Taï forest region) of Côte d'Ivoire. This is in contrast with lower prevalences obtained from a previous spatial analysis using historical data focussing on children aged $<16$ years [22]. Recent environmental transformations, such as rice farming in the north [44] and progression of deforestation in the Taï forest in the south-west, led to increased population densities [45, 46], which might explain the change in P. falciparum prevalence rates in these areas. However, differences in survey designs and large heterogeneities of historical data must be considered to deepen the understanding of potential changes in P. falciparum prevalence and parasitaemia in space and time [47]. The design of the present study allowed us to have more uniformly distributed data across the country than before, and hence, prediction uncertainty was minimized.

\section{Conclusion}

This study provided a comprehensive analysis on the spatial distribution of $P$. falciparum infection among school-aged children across Côte d'Ivoire. Given the high burden of $P$. falciparum infections in the schoolaged population, there is a need for intervention strategies that also target this age group. Notwithstanding, since the end of 2014, the national malaria control programme in Côte d'Ivoire is making LLINs available to the entire population, including school-aged children, thus an important step is taken to tackle the malaria burden in this specific age group. The produced smooth $P$. falciparum prediction map, in conjunction with uncertainty estimates, represent useful tools for scaling up current and future malaria control interventions. Future predictive risk profiling should include other factors such as population density and more detailed information on intervention coverage in order to better understand the impact of ongoing malaria interventions.

\section{Additional file}

Additional file 1: Bayesian geostatistical stochastic search variable selection. (DOCX $22 \mathrm{~kb}$ )

\section{Acknowledgements}

Thanks are addressed to all education officers, school directors, teachers and children and their parents/guardians for their participation. Particular thanks go to the laboratory technicians (Mahamadou Traoré, Sadikou Touré, Jean K. Brou and Amani Lingué) and drivers (Paul Kaboré, 
Mangoh Tano, Guillaume Toukou, Jean Akoubé and Abou Bamba) for their commitment and expert skills.

\section{Funding}

This study was financed by the Swiss National Science Foundation (SNSF, project no. 32003B-132949) and through an individual grant to CAH by the "Programme d'Appui Stratégique à la Recherche Scientifique" (PASRES, project no 47_2009). EKN and JU acknowledge financial support from SNSF (project no. IZ70Z0_123900). PV acknowledges the European Research Council (3231805-IMCCA) and the Swiss programme for Research on Global Issues for Development (project no. IZ01Z0-147286).

\section{Availability of data and materials}

The datasets used for analysis of the study are available from the corresponding author on reasonable request.

\section{Authors' contributions}

$\mathrm{CAH}, \mathrm{RBY}, \mathrm{EH}, \mathrm{PBN}, \mathrm{KDS}, \mathrm{GS}$ and GR implemented the study. BGK, SBA and AF assisted in the preparation for execution of the study. EKN, JU, PV and GR conceived and designed the study. KDS, GS and GR supervised the study. $\mathrm{CAH}, \mathrm{FC}$ and PV analysed the data. CAH, FC, RBY, EH, PBN and GR contributed to the data management. $C A H, F C, J U, P V$ and $G R$ drafted the manuscript. All authors read, revised and approved the final manuscript.

\section{Competing interests}

The authors declare that they have no competing interests.

\section{Consent for publication}

Not applicable.

\section{Ethics approval and consent to participate}

The study protocol was approved by the ethics committees of Basel (EKBB; reference no. 30/11) and Côte d'Ivoire (reference no. 09-2011/ MSHP/CNER-P). Additionally, permission to carry out this study was obtained from the Ministry of National Education. Written informed consent was obtained from parents or legal guardians of participating children, while children assented orally. Participation was voluntary, and hence, withdrawal was possible anytime without further obligation. Parasitological and questionnaire data were coded and treated confidentially. All febrile children (tympanic temperature $\geq 38{ }^{\circ} \mathrm{C}$ ) with a positive result for Plasmodium infection were treated with $A C T$, according to recommendations put forth by $\mathrm{WHO}$ and national policies [48].

\section{Author details}

${ }^{1}$ Unité de Formation et de Recherche Sciences de la Nature, Université Nangui Abrogoua, 02 BP 801, Abidjan 02, Côte d'Ivoire. ²Département Environnement et Santé, Centre Suisse de Recherches Scientifiques en Côte d'Ivoire, 01 BP 1303, Abidjan 01, Côte d'Ivoire. ³ Department of Epidemiology and Public Health, Swiss Tropical and Public Health Institute, P.O. Box, $\mathrm{CH}-4002$ Basel, Switzerland. ${ }^{4}$ University of Basel, P.O. Box, CH-4003 Basel, Switzerland. ${ }^{5}$ Unité de Formation et de Recherche Biosciences, Université Félix Houphouët-Boigny, 22 BP 522, Abidjan 22, Côte d'Ivoire. ${ }^{6}$ Programme National de Santé Scolaire et Universitaire, 01 BP 1725, Abidjan 01, Côte d'Ivoire. ${ }^{7}$ Vector Group, Liverpool School of Tropical Medicine, Liverpool L3 5QA, UK. ${ }^{8}$ Institut Pierre Richet de Bouaké, Institut National de Santé Publique, BP 1500, Bouaké, Côte d'Ivoire. ${ }^{9}$ Programme National de Lutte contre le Paludisme, Ministère de la Santé et de la Lutte contre le SIDA, BP V 4, Abidjan, Côte d'Ivoire.

\section{Received: 3 February 2016 Accepted: 25 August 2016} Published online: 07 September 2016

\section{References}

1. WHO. World Malaria Report. Geneva: World Health Organization; 2015

2. Vos T, Barber RM, Bell B, Bertozzi-Villa A, Biryukov S, Bolliger I, Charlson F, Davis A, Degenhardt L, Dicker D, Duan L, Erskine H, Feigin VL, Ferrari AJ,Fitzmaurice C, Fleming T, Graetz N, Guinovart C, Haagsma J, Hansen GM, Hanson SW Heuton KR, Higashi H, Kassebaum N, Kyu H, Laurie E, Liang X, Lofgren K, Lozano R, Maclntyre MF, et al. Global, regional, and national incidence, prevalence, and years lived with disability for 301 acute and chronic diseases and injuries in 188 countries, 1990-2013: a systematic analysis for the Global Burden of Disease study 2013. Lancet. 2015:386:743-800.

3. Sachs J, Malaney P. The economic and social burden of malaria. Nature. 2002;415:680-5.

4. Chima Rl, Goodman CA, Mills A. The economic impact of malaria in Africa: a critical review of the evidence. Health Policy. 2003;63:17-36.

5. Guinovart C, Navia MM, Tanner M, Alonso PL. Malaria: burden of disease. Curr Mol Med. 2006:6:137-40.

6. Bhatt S, Weiss DJ, Cameron E, Bisanzio D, Mappin B, Dalrymple U, Battle KE, Moyes CL, Henry A, Eckhoff PA, Wenger EA, Briët O, Penny MA, Smith TA, Bennett A, Yukich J, Eisele TP, Griffin JT, Fergus CA, Lynch M, Lindgren F, Cohen JM, Murray CLJ, Smith DL, Hay SI, Cibulskis RE, Gething PW. The effect of malaria control on Plasmodium falciparum in Africa between 2000 and 2015. Nature. 2015;526:207-11.

7. Hay SI, Snow RW. The Malaria Atlas Project: developing global maps of malaria risk. PLoS Med. 2006;3:e473.

8. Giardina F, Kasasa S, Sié A, Utzinger J, Tanner M, Vounatsou P. Effects of vector-control interventions on changes in risk of malaria parasitaemia in sub-Saharan Africa: a spatial and temporal analysis. Lancet Glob Health. 2014;2:e601-615.

9. Hay SI, Snow RW, Rogers DJ. From predicting mosquito habitat to malaria seasons using remotely sensed data: practice, problems and perspectives. Parasitol Today. 1998;14:306-13.

10. Rogers DJ, Randolph SE, Snow RW, Hay SI. Satellite imagery in the study and forecast of malaria. Nature. 2002;415:710-5.

11. Kalluri S, Gilruth P, Rogers D, Szczur M. Surveillance of arthropod vectorborne infectious diseases using remote sensing techniques: a review. PLoS Pathog. 2007:3:e116.

12. Vounatsou P, Raso G, Tanner M, N'Goran EK, Utzinger J. Bayesian geostatistical modelling for mapping schistosomiasis transmission. Parasitology. 2009;136:1695-705.

13. Beck LR, Rodriguez MH, Dister SW, Rodriguez AD, Rejmankova E, Ulloa A, Meza RA, Roberts DR, Paris JF, Spanner MA, Washino RK, Hacker C, Legters LJ. Remote sensing as a landscape epidemiologic tool to identify villages at high risk for malaria transmission. Am J Trop Med Hyg. 1994;51:271-80.

14. Hay SI, Snow RW, Rogers DJ. Predicting malaria seasons in Kenya using multitemporal meteorological satellite sensor data. Trans R Soc Trop Med Hyg. 1998;92:12-20.

15. Lindsay SW, Parson L, Thomas CJ. Mapping the ranges and relative abundance of the two principal African malaria vectors, Anopheles gambiae sensu stricto and An. arabiensis, using climate data. Proc R Soc Lond B. 1998;265:847-54

16. Jeanne I. Paludisme et schistosome: deux exemples d'utilisation des systèmes d'information géographique et de la télédétection à Madagascar. Bull Soc Pathol Exot. 2000:93:208-14.

17. Brooker S, Leslie T, Kolaczinski K, Mohsen E, Mehboob N, Saleheen S, Khudonazarov J, Freeman T, Clements A, Rowland M, Kolaczinski J. Spatial epidemiology of Plasmodium vivax, Afghanistan. Emerg Infect Dis. 2006;12 1600-2.

18. Kleinschmidt I, Bagayoko M, Clarke GPY, Craig M, Le Sueur D. A spatial statistical approach to malaria mapping. Int J Epidemiol. 2000;29:355-61.

19. Gosoniu L, Vounatsou P, Sogoba N, Maire N, Smith T. Mapping malaria risk in West Africa using a Bayesian nonparametric non-stationary model. Comput Stat Data Anal. 2009;53:3358-71.

20. Silué KD, Raso G, Yapi A, Vounatsou P, Tanner M, N'Goran EK, Utzinger J. Spatially-explicit risk profiling of Plasmodium falciparum infections at a small scale: a geostatistical modelling approach. Malar J. 2008;7:111.

21. Raso G, Silué KD, Vounatsou P, Singer BH, Yapi A, Tanner M, Utzinger J, N'Goran EK. Spatial risk profiling of Plasmodium falciparum parasitaemia in a high endemicity area in Côte d'Ivoire. Malar J. 2009:8:252.

22. Raso G, Schur N, Utzinger J, Koudou BG, Tchicaya ES, Rhoner F, N'Goran EK, Silué KD, Matthys B, Assi S, Tanner M, Vounatsou P. Mapping malaria risk among children in Côte d'Ivoire using Bayesian geo-statistical model. Malar J. 2012;11:160

23. Gosoniu L, Vounatsou P, Sogoba N, Smith T. Bayesian modelling of geostaitistical malaria risk data. Geospat Health. 2006;1:127-39.

24. Mabaso MLH, Vounatsou P, Midzi S, Da Silva J, Smith T. Spatio-temporal analysis of the role of climate in inter-annual variation of malaria incdence in Zimbabwe. Int J Health Geograph. 2006;5:20.

25. Sogoba N, Vounatsou P, Doumbia S, Bagayoko M, Touré MB, Sissoko IM, Traore SF, Touré YT, Smith T. Spatial analysis of malaria transmission 
parameters in the rice cultivation area of office du Niger, Mali. Am J Trop Med Hyg. 2007;76:1009-15.

26. Kasasa S, Asoala V, Gosoniu L, Anto F, Adjuik M, Tindana C, Smith T, OwusuAgyei $S$, Vounatsou P. Spatio-temporal malaria transmission patterns in Navrongo demographic surveillance site, northern Ghana. Malar J. 2013;12:63.

27. Hay SI, Guerra CA, Gething PW, Patil AP, Tatem AJ, Noor AM, Kabaria CW, Manh BH, Elyazar IRF, Brooker S, Smith DL, Moyeed RA, Snow RW. A world malaria map: Plasmodium falciparum endemicity in 2007. PLoS Med. 2009;6: e1000048.

28. Gething PW, Patil AP, Smith DL, Guerra CA, Elyazar IRF, Johnston GL, Tatem AJ, Hay SI. A new world malaria map: Plasmodium falciparum endemicity in 2010. Malar J. 2011;10:378.

29. PNLP-Cl: Evaluation des besoins (needs assessment). Initiative Faire Reculer le Paludisme (Roll Back Malaria), draft 1 du rapport needs assessment. Programme National de Lutte contre le Paludisme Côte d'Ivoire (PNLP-CI). 2008;103.

30. Yapi RB, Hürlimann E, Houngbedji CA, N'Dri PB, Silué KD, Soro G, Kouamé FN, Vounatsou P, Fürst T, N'Goran EK, Utzinger J, Raso G. Infection and coinfection with helminths and Plasmodium among school children in Côte d'Ivoire: results from a national cross-sectional survey. PLoS Negl Trop Dis. 2014;8:e2913.

31. Houngbedji CA, N'Dri PB, Hürlimann E, Yapi RB, Silué KD, Soro G, Koudou BG, Acka CA, Assi S-B, Vounatsou P, N'Goran EK, Fantodji A, Utzinger J, Raso G. Disparities of Plasmodium falciparum infection, malaria-related morbidity and access to malaria prevention and treatment among school-aged children: a national cross-sectional survey in Côte d'Ivoire. Malar J. 2015;14:7

32. Hürlimann E, Houngbedji CA, Yapi RB, N'Dri PB, Silué KD, Soro G, Kouamé FN, Fürst T, Utzinger J, N'Goran EK, Raso G. Health-related quality of life among school children with parasitic infections: findings from a national cross-sectional survey in Côte d'Ivoire. PLoS Negl Trop Dis. 2014;8:e3287.

33. Diggle PJ, Tawn JA, Moyeed RA. Model-based geostatistics. J R Stat Soc Ser C Appl Stat. 1998;47:299-326

34. Montresor A, Crompton DWT, Gyorkos TW, Savioli L. Helminth control in school-age children: a guide for managers of control programmes in planning. Geneva: World Health Organization; 2002.

35. George El, McCulloch RE. Variable selection via Gibbs sampling. J Am Stat Assoc. 1993;88:881-9.

36. Chammartin F, Scholte RGC, Malone JB, Bavia ME, Nieto P, Utzinger J, Vounatsou P. Modelling the geographical distribution of soil-transmitted helminth infections in Bolivia. Parasit Vectors. 2013;6:152.

37. Scheipl F, Fahrmeir L, Kneib T. Spike-and-slab priors for function selection in structured additive regression models. J Am Stat Assoc. 2012;107:1518-32.

38. Cressie N. The origins of kriging. Math Geol. 1990;22:239-52.

39. Krefis AC, Schwarz NG, Nkrumah B, Acquah S, Loag W, Oldeland J, Sarpong N, Adu-Sarkodie Y, Ranft U, May J. Spatial analysis of land cover determinants of malaria incidence in the Ashanti region, Ghana. PLoS One. 2011;6:e17905.

40. Brooker S, Clarke S, Njagi JK, Polack S, Mugo B, Estambale B, Muchiri E, Magnussen P, Cox J. Spatial clustering of malaria and associated risk factors during an epidemic in a highland area of western Kenya. Trop Med Int Health. 2004;9:757-66.

41. Gallup JL, Sachs JD. The economic burden of malaria. Am J Trop Med Hyg 2001;64:85-96.

42. Worrall E, Basu S, Hanson K. Is malaria a disease of poverty? A review of the literature. Trop Med Int Health. 2005;10:1047-59.

43. Utzinger J, Keiser J. Urbanisation and tropical health - then and now. Ann Trop Med Parasitol. 2006;100:517-33.

44. Doannio JMC, Dossou-Yovo J, Diarrassouba S, Rakotondraibé ME, Chauvancy G, Chandre F, Rivière F, Carnevale P. La dynamique de la transmission du paludisme à Kafiné, un village rizicole en zone de savane humide de Côte d'Ivoire. Bull Soc Pathol Exot. 2002;95:11-6.

45. Nzeyimana I, Henry M-C, Dossou-Yovo J, Doannio JMC, Diawara L, Carnevale P. Épidémiologie du paludisme dans le sud-ouest forestier de la Côte d'Ivoire (région de Taï). Bull Soc Pathol Exot. 2002;95:89-94.

46. Guerra CA, Snow RW, Hay SI. A global assessment of closed forests, deforestation and malaria risk. Ann Trop Med Parasitol. 2006:100:189-204.

47. Chammartin F, Hürlimann E, Raso G, N'Goran EK, Utzinger J, Vounatsou P. Statistical methodological issues in mapping historical schistosomiasis survey data. Acta Trop. 2013;128:345-52.

48. WHO. Guidelines for the treatment of malaria. Geneva: World Health Organization; 2006.

\section{Submit your next manuscript to BioMed Central and we will help you at every step:}

- We accept pre-submission inquiries

- Our selector tool helps you to find the most relevant journal

- We provide round the clock customer support

- Convenient online submission

- Thorough peer review

- Inclusion in PubMed and all major indexing services

- Maximum visibility for your research

Submit your manuscript at www.biomedcentral.com/submit
Biomed Central 